\title{
Impact of Depression on Quality of Life Results in Patients Following Acute Coronary Syndrome Treated with Percutaneous Coronary Intervention (PCI)
}

\author{
Jankowska Polańska Beata $^{1 \star}$, Uchmanowicz Izabella ${ }^{1}$, Dudek Krzysztof ${ }^{2}$ and Łoboz- Grudzień Krystyna ${ }^{1,2}$ \\ ${ }^{1}$ Clinical Nursing Division, Public Health Faculty, Medical University of Wrocław, Poland \\ ${ }^{3}$ Department of Cardiology T. Marciniak Hospital, Wrocław, Poland \\ *Corresponding author: $\mathrm{Dr}$ Beata Jankowska -Polańska, Clinical Nursing Division, Public Health Faculty, Medical University of Wrocław, Poland, \\ bianko@poczta.onet.pl
}

Received date: October 2, 2014; Accepted date: December 4, 2014; Published date: December 10, 2014

Copyright: @ 2014 Beata JP, et al. This is an open-access article distributed under the terms of the Creative Commons Attribution License, which permits unrestricted use, distribution, and reproduction in any medium, provided the original author and source are credited.

\begin{abstract}
The purpose of study was to evaluate the impact of depressive symptoms on the QoL in patients following acute coronary syndrome treated with percutaneous coronary intervention $(\mathrm{PCl})$ at week one of hospitalization and 6 months following ACS.

\section{Methods}

The study population included 140 patients hospitalized for acute coronary syndrome who underwent $\mathrm{PCl}$. Depression was evaluated using the Beck Depression Index, which is a self-scoring test for symptoms and severity of depression composed of 21 questions. QoL was evaluated with the use of the Mac New questionnaire, specifically designed for cardiology patients. The QoL evaluation in all Mac New dimensions in the depressed and not depressed groups was statistically different both at baseline and at 6-month follow up. At baseline and at the 6month follow-up, the mean Emotional Dimension, Physical Dimension, Social Dimension and evaluation of the General Quality of Life dimension the results were lower in the depressed group compared with the not depressed group. The dynamics of change in QoL at 6 months following $\mathrm{PCl}$ was verified using the Wilcoxon test and a statistically significant improvement in quality of life was found in all Mac New dimensions in both groups. However, the dynamics were more beneficial in the depressed group. Depression in ACS patients has a strong negative effect on QoL both in early and late observations. Early depression, on the other hand, is a statistically significant and independent predictor of a lower QoL outcome. As such, diagnosis and treatment of depression in patients hospitalized with ACS should become a therapeutic standard.
\end{abstract}

Keywords: Depression; Acute coronary syndrome; Quality of life

\section{Introduction}

The purpose of the treatment of acute coronary syndromes (ACS) is improvement in patients' health, which means that it is designed not only to reduce mortality, but also to improve functional outcomes and quality of life in this group of patients [1]. Symptoms of depression can be observed in $45 \%$ of patients hospitalized for acute coronary syndromes. These greatly hinder the achievement of the desired therapeutic goal, increase the risk of early and late mortality, and impair patient quality of life [2,3]. A recent meta-analysis of 22 studies suggested that the effects of depression following myocardial infarction on cardiac prognosis were at least partly confounded by the severity of the infarction. Overall, post-myocardial infarction depression was associated with a 2-2.5 times increased risk of all-cause mortality, cardiac mortality, and new cardiovascular events [4].

Early diagnosis and an individually designed treatment plan help improve patient health and functional outcomes and may reduce the cost of treatment. According to the American Heart Association, patients with heart diseases should be evaluated for early depression symptoms [5]. Patients with depression respond less well to treatment and are not actively involved in the therapeutic process [2].
Many researchers believe that quality of life (QoL) is a more important mortality predictor than other clinical health indicators (ejection fraction, stress test) in patients with acute coronary syndrome [6].

Both depression and quality of life are indicators affecting the therapeutic outcome of ACS therapy. There is a negative correlation between depression and quality of life, as depression impairs quality of life to an extent similar to or even greater than many chronic diseases. Research on depression and how it affects quality of life has recently been the subject of many medical studies [7-9]. There is evidence that in some patient's depression may harm the improvement in quality of life even following a successful coronary angioplasty [10].

To date there have been few studies evaluating the effects of depression on quality of life in patients following acute coronary syndrome treated with coronary angioplasty, and none using the Mac New questionnaire to evaluate quality of life in depressed patients. The purpose of this study is to evaluate the impact of depression on the quality of life in patients following acute coronary syndrome treated with percutaneous coronary intervention (PCI) at week one of hospitalization and 6 months following infarction. 


\section{Methods}

The study population numbered 140 patients (70 women and 70 men) aged from 32 to 95 years (average age 63.4) hospitalized for acute coronary syndrome (116 patients with ST-segment elevation (STEMI), 24 patients without ST-segment elevation (NSTEMI)) who underwent percutaneous transluminal coronary angioplasty (PCI) at the Department of Cardiology between September 2008 and March 2009. The clinical diagnosis of acute coronary syndrome was based on the criteria generally accepted by the Polish Cardiac Society and the European Society of Cardiology. All patients gave informed consent to their participation in the study. Depressiveness was evaluated using the Beck Depression Index (BDI), which is a self-scoring test for symptoms and severity of depressiveness composed of 21 questions and offering four variant answers scored at from 0 to 3 points. The higher the score, the worse the mental condition of the patient. Quality of life was evaluated with the use of the Mac New questionnaire, specifically designed for cardiology patients.

The Mac New questionnaire contains 27 questions, making up three dimensions of quality of life in cardiology patients: physical, mental and social. Patient responses are measured on a 7-point Likert scale, where a lower score indicates a worse quality of life. It is also possible to measure the global level of quality of life of each patient. In order to investigate correlation between depressiveness and quality of life, the patients were divided into two groups. All patients scoring more than 10 points on the Beck Depression Index were placed in the depressiveness group. This approach was in conformity with the guidelines of the authors of the Index and had been used in many previous studies [2,11-13].

This was a prospective study, and the quality of life and depressiveness level were evaluated twice, specifically at week one of PCI and after 6 months. The study was approved by the Bioethics Committee of the Wrocław Medical University (approval no. KB-234/2009). Baseline socio-demographic data such as sex, marital status, education and source of income were collected from patients. All of the patients were given a written questionnaire providing detailed information on the study, in which they agreed to participate, and they were assured that the study was anonymous. Both at week one and 6 months after the procedure the questionnaires were filled out in the presence of an investigator. The evaluation coming 6 months after PCI was performed at the Cardiology Outpatient Clinic, where all patients were subject to checkups. The follow-up evaluation taking place 6 months following PCI included only 67 women and 70 men with acute coronary syndrome treated with coronary angioplasty since three of the women who had been admitted to the baseline evaluation had died 5-6 months later. Analysed in addition were sociodemographic and clinical predictors able to affect quality of life and depressiveness in patients hospitalized for acute coronary syndrome.

Study predictors included socio-demographic factors (sex, age, marital status, education, occupational activity), as well as risk factors such as smoking, obesity (body mass index (BMI) $\geq 30 \mathrm{~kg} / \mathrm{m} 2$ ), lipid metabolism (definition of dyslipidaemia was based on Adult Treatment Panel III criteria and the following levels were assumed: triglycerides $\geq 150 \mathrm{mg} / \mathrm{dL}$; HDL cholesterol $<40 \mathrm{mg} / \mathrm{dL}(1.0 \mathrm{mmol} / \mathrm{L})$ in men and $45 \mathrm{mg} / \mathrm{dL}(1.3 \mathrm{mmol} / \mathrm{L})$ in women; total cholesterol $\geq 190$ $\mathrm{mg} / \mathrm{dL} ; \mathrm{LDL}$ cholesterol $\geq 115 \mathrm{mg} / \mathrm{dL}$ ), diabetes (diagnosed based on history of regular hypoglycemic medications being taken and / or results of laboratory tests, fasting $\geq 126 \mathrm{mg} / \mathrm{dl}(7.0 \mathrm{mmol} / \mathrm{l})$ and / or oral glucose tolerance test $\geq 200 \mathrm{mg} / \mathrm{dl}(11.1 \mathrm{mmol} / \mathrm{l})$, hypertension
(Systolic blood pressure (SBP) $\geq 140 \mathrm{~mm} \mathrm{Hg}$ and Diastolic blood pressure (DBP) $\geq 90 \mathrm{mmHg}$ ), and stress exposure.

\section{Study inclusion criteria}

Each patient, who agreed to take part in the study, made selfassessment questionnaire that assess depressive symptoms and their severity. Each patient was informed in detail about the manner of research to be conducted and what their participation would involve. Each patient had the opportunity to ask researchers any questions and was provided with clear and comprehensive responses. Written information addressed the issues connected with the subject of the research, its purpose, rules of conduct, benefits and risks as well as the patients' possible resignation from the study at any time and at any stage.

The patients were qualified to the study according to the following criteria:

- - diagnosed acute coronary syndrome and consent to performance of PCI

- State of awareness allowing filling in the form,

- - Communicativeness in Polish

- The patients with the following symptoms were excluded from the study:

- - History of previous cardiovascular episodes

- Sudden circulatory arrest

- - Ventricular fibrillation

- - Cardiogenic shock and those who refused to take part in it.

- - Lack of patient's consent

- - Diagnosed depression at baseline study or antidepressant treatment

\section{Statistical analysis}

The statistical overview was based on a statistical analysis of measurable (quantitative) and non-measurable (qualitative) variables.

The dichotomous variables included patient sex (Female (F), Men $(\mathrm{M})$ ) and depression (BDI $>10)$ or lack of depression (BDI $<10)$. The measurable (quantitative) variables were quality of life measured using the Mac New questionnaire in all three dimensions plus the general result.

The statistical analysis of questionnaire results involved the following tasks:

The distribution of all measurable variables was tested for difference from the normal distribution. Evaluation of this used the ShapiroWilks tests. The assumed critical significance level was $\mathrm{P}=0.05$. The mean values and 95\% confidence interval for the means were established for all measurable variables (QoL scores). To establish the significance of the differences in mean values in both groups (sex, depression) for variables with normal distribution and homogeneous variance we used the independent samples t-test. To establish the significance of the differences in mean values in both groups (different sex, presence or absence of depression) for variables with distribution different from the normal or non-homogeneous variance we used the non-parametric U Mann-Whitney test. To establish the significance of the differences in mean values in the two follow-up periods (at week one and after 6 months) we used the paired samples t-test or the Wilcoxon test. To evaluate the independence of nominal variables (QoL predictors) and depression we used contingency tables and 
Citation: Beata JP, Izabella U, Krzyszt0of U, Krystyna LG (2014) Impact of Depression on Quality of Life Results in Patients Following Acute Coronary Syndrome Treated with Percutaneous Coronary Intervention (PCI). J Nurs Care 3: 222. doi:10.4172/2167-1168.1000222

Page 3 of 7

Pearson's $\chi 2$ independence test. To evaluate the effect of predictors (nominal and quantitative variables) on quality of life evaluated using the MacNew questionnaire we applied multiple regression analysis. To establish the correlation between quality of life (MacNew) and depression (BDI) outcomes we used Spearman's rank coefficient (rS) and the beta coefficient of regression. To verify the hypothesis that there was no correlation between the outcomes of the MacNew and BDI questionnaires $(r S=0)$ we used the Student's t-test.
The STATISTICA v. 9,0 software package was used for calculations.

\section{Patient characteristics}

The characteristics of participants in the depressive symptoms and not depressive symptoms groups who were followed at both baseline and 6 months are described in Table 1.

\begin{tabular}{|c|c|c|c|c|c|c|}
\hline \multirow[t]{2}{*}{ Variable } & \multicolumn{2}{|c|}{ Depressed $(N=88)$} & \multicolumn{2}{|c|}{ Not depressed $(\mathrm{N}=52)$} & \multicolumn{2}{|c|}{ Analysis } \\
\hline & N & $\%$ & N & $\%$ & $x^{2}$ & $p$ \\
\hline Mean age & 65.2 & $62.5-67.9$ & 60.4 & $57.3-63.5$ & 2.227 & 0.02 \\
\hline Female & 52 & 59.1 & 18 & 34.6 & 6.88 & 0.01 \\
\hline Education & & & & & 3.11 & 0.38 \\
\hline Primary & 23 & 26.1 & 10 & 19.2 & & \\
\hline basic vocational & 31 & 35.2 & 24 & 46.2 & & \\
\hline Secondary & 26 & 29.5 & 11 & 21.2 & & \\
\hline higher & 8 & 9.1 & 7 & 13.5 & & \\
\hline Source of income & & & & & 2.18 & 0.54 \\
\hline Employment & 21 & 23.9 & 18 & 34.6 & & \\
\hline disabled pension & 15 & 17.0 & 6 & 11.5 & & \\
\hline Pension & 50 & 56.8 & 27 & 51.9 & & \\
\hline unemployment benefit & 2 & 2.3 & 1 & 1.9 & & \\
\hline Physical work & 30 & 34.1 & 24 & 46.2 & 0.39 & 0.53 \\
\hline Living in a small town & 24 & 27.3 & 8 & 15.4 & 1.99 & 0.16 \\
\hline Single (spinster, widow) & 44 & 50.0 & 11 & 21.2 & 10.22 & $<0.01$ \\
\hline Occasionally exercising & 70 & 79.5 & 38 & 73.1 & 0.45 & 0.50 \\
\hline Smoking & 61 & 69.3 & 43 & 82.7 & 2.40 & 0.12 \\
\hline Diabetes & 34 & 38.6 & 9 & 17.3 & 6.02 & 0.01 \\
\hline Hypertension & 52 & 59.1 & 24 & 46.2 & 1.71 & 0.19 \\
\hline Stress & 36 & 40.9 & 17 & 32.7 & 0.62 & 0.43 \\
\hline Genetic predisposition & 44 & 50.0 & 35 & 67.3 & 3.31 & 0.07 \\
\hline
\end{tabular}

Table 1: Demographic and clinical characteristics of 140 patients with and without depression at week one following coronary angioplasty.

There were more women in the depressive symptoms group (group I; $\mathrm{N}=88$ ) than in the not depressive symptoms group (group II; $\mathrm{N}=52$ ) compared with men $(59.1 \%$ vs. $36.4 \% ; \mathrm{P}=0.01)$. Furthermore, compared with the not depressive symptoms group, patients in the depressive symptoms group were more often than not single $(43.2 \%$ vs. $19.2 \%$ widow/widower; $\mathrm{P}<0.01)$, retired $(56.8 \%$ vs. $27 \%$; ns) or on a disability pension ( $17 \%$ vs. $6 \%$; ns), exercising occasionally, if at all, and frequently predisposed to diabetes $(38.6 \%$ vs. $17.3 \% ; \mathrm{P}<0.01)$ or hypertension (59.1\% vs. $46.2 \%$; ns). In addition, patients with depressive symptoms were on average 5 years older than patients without depressive symptoms. The mean self-scoring result on the BDI questionnaire in group I (depressive symptoms) was $17.8(16.4 \div$
19.3), while in group II (without depressive symptoms) it was 6.8 (5.9 $\div 7.6$ ).

The socio-demographic characteristics revealed statistically significant differences between both groups with regard to age, sex and marital status (demographic variables) and diabetes (clinical variables). These variables were included in the analysis as control variables in subsequent evaluation of the relationship between depressive symptoms and quality of life after 6 months. 
Citation: Beata JP, Izabella U, Krzyszt0of U, Krystyna LG (2014) Impact of Depression on Quality of Life Results in Patients Following Acute Coronary Syndrome Treated with Percutaneous Coronary Intervention (PCI). J Nurs Care 3: 222. doi:10.4172/2167-1168.1000222

Page 4 of 7

\section{The relationship between depression and quality of life}

The quality of life evaluation in all Mac New dimensions in the depressive symptoms and not depressive symptoms groups was statistically different both at baseline and at 6-month follow up. At baseline, the mean Emotional Dimension (ED) value in the depressive symptoms group was 3.67 (3.44-3.89), significantly lower than the not depressive symptoms group 4.75 (4.47-5.04) $(\mathrm{P}<0.001)$. Similar results were obtained in the Physical Dimension (PD), i.e. 3.03 (2.80-3.29) in group I vs. $4.19(3.80-4.58)(\mathrm{P}<0.001)$ in group II, and in the Social Dimension (SD), i.e. 3.70 (3.44-3.95) in group I vs. 4.92 (4.55-5.29) $(\mathrm{P}<0.001)$ in group II. At baseline evaluation of the General Quality of Life dimension (GQoL), the results were also lower in the depressive symptoms group, i.e. 3.48 (3.25-3.71), compared with the not depressive symptoms group, i.e. $4.63(4.29-4.96)(\mathrm{P}<0.001)$ (Table 2).

\begin{tabular}{|c|c|c|c|c|c|c|c|c|c|c|}
\hline \multirow[t]{3}{*}{ MacNew } & \multicolumn{5}{|c|}{ After one week $(N=140)$} & \multicolumn{5}{|c|}{ After 6 months $(N=140)$} \\
\hline & \multicolumn{2}{|c|}{$\begin{array}{l}\text { Depressed } \\
(\mathrm{N}=88)\end{array}$} & \multicolumn{2}{|c|}{$\begin{array}{l}\text { Not depressed } \\
(\mathrm{N}=52)\end{array}$} & \multirow{2}{*}{$\begin{array}{l}\mathrm{P}^{*} \\
\text { Mean }\end{array}$} & \multicolumn{2}{|c|}{$\begin{array}{l}\text { Depressed } \\
(\mathrm{N}=88)\end{array}$} & \multicolumn{2}{|c|}{$\begin{array}{l}\text { Not depressed } \\
(\mathrm{N}=52)\end{array}$} & \multirow[t]{2}{*}{$\mathrm{P}^{*}$} \\
\hline & Mean & $95 \% \mathrm{Cl}$ & Mean & $95 \% \mathrm{Cl}$ & & $95 \% \mathrm{Cl}$ & Mean & $95 \% \mathrm{Cl}$ & & \\
\hline ED & 3.67 & $3.44-3.89$ & 4.75 & $4.47-5.04$ & $<0.001$ & 4.73 & $4.41 \div 5.14$ & 5.22 & $4.91 \div 5.43$ & 0.018 \\
\hline PD & 3.05 & $2.80-3.29$ & 4.19 & $3.80-4.58$ & $<0.001$ & 4.24 & $4.04 \div 4.51$ & 4.79 & $4.33 \div 5.24$ & 0.005 \\
\hline SD & 3.70 & $3.44-3.95$ & 4.92 & $4.55-5.29$ & $<0.001$ & 4.79 & $4.53 \div 5.02$ & 5.42 & $4.92 \div 5.73$ & 0.003 \\
\hline G QoL & 3.48 & $3.25-3.71$ & 4.63 & $4.29-4.96$ & $<0.001$ & 4.59 & $4.62 \div 5.38$ & 5.01 & $4.58 \div 5.41$ & 0.006 \\
\hline
\end{tabular}

Table 2: Quality of life in 140 patients with and without depression following hospitalization for ACS.

* Mann-Whitney Test; ED-Emotional Dimension; PD - Physical Dimension; SD - Social Dimension; GQoL - General Quality of Life.

At the 6-month follow-up, the outcomes for quality of life in the depressive symptoms group were again lower compared with the not depressive symptoms group in all MacNew dimensions (Table 2). The dynamics of change in quality of life at 6 months following PCI was verified using the Wilcoxon test and a statistically significant improvement in quality of life was found in all MacNew dimensions in both groups. However, the dynamics were more beneficial in the depressive symptoms group (Table 3 ).

\begin{tabular}{|c|c|c|c|c|c|c|c|c|c|c|}
\hline \multirow[t]{3}{*}{ Mac New } & \multicolumn{5}{|c|}{$\begin{array}{l}\text { Depressed } \\
(\mathrm{N}=88)\end{array}$} & \multicolumn{5}{|c|}{$\begin{array}{l}\text { Not depressed } \\
(N=52)\end{array}$} \\
\hline & \multicolumn{2}{|c|}{ After one week } & \multicolumn{2}{|c|}{ After 6 months } & \multirow{2}{*}{$\frac{P^{*}}{\text { Mean }}$} & \multicolumn{2}{|c|}{ After one week } & \multicolumn{2}{|c|}{ After 6 months } & \multirow[t]{2}{*}{$P^{*}$} \\
\hline & Mean & $95 \% \mathrm{Cl}$ & Mean & $95 \% \mathrm{Cl}$ & & $95 \% \mathrm{Cl}$ & Mean & $95 \% \mathrm{Cl}$ & & \\
\hline ED & 3.67 & $3.44-3.89$ & 4.73 & $4.41 \div 5.14$ & $<0.001$ & 4.75 & $4.47-5.04$ & 5.22 & $4.91 \div 5.43$ & $<0.001$ \\
\hline PD & 3.05 & $2.80-3.29$ & 4.24 & $4.04 \div 4.51$ & $<0.001$ & 4.19 & $3.80-4.58$ & 4.79 & $4.33 \div 5.24$ & $<0.001$ \\
\hline SD & 3.70 & $3.44-3.95$ & 4.79 & $4.53 \div 5.02$ & $<0.001$ & 4.92 & $4.55-5.29$ & 5.42 & $4.92 \div 5.73$ & $<0.001$ \\
\hline G QoL & 3.48 & $3.25-3.71$ & 4.59 & $4.62 \div 5.38$ & $<0.001$ & 4.63 & $4.29-4.96$ & 5.01 & $4.58 \div 5.41$ & $<0.001$ \\
\hline
\end{tabular}

Table 3:Dynamics of change in quality of life in groups I and II.

Wilcoxon Matched Pairs Test; ED-Emotional Dimension; PD Physical Dimension; SD - Social Dimension; GQoL - General Quality of Life

The strength of the correlation between quality of life (evaluated using the Mac New questionnaire after 6 months) and depressive symptoms (evaluated using the BDI questionnaire at week one) was established on the basis of Spearman's rank coefficient (rS) and the beta coefficient of linear regression (Table 4), and statistically significant negative correlation was fund in all dimensions $(\mathrm{P}<$ 0.0001).

\begin{tabular}{|l|l|l|l|l|l|}
\hline Mac New & rS & $\mathbf{9 5 \%}$ Cl for rS & beta & $\mathbf{9 5 \%}$ Cl for beta & $\mathbf{P}$ \\
\hline ED & -0.379 & $(-0.513 \div-0.228)$ & -0.064 & $(-0.075 \div-0.054)$ & $<0.0001$ \\
\hline PD & -0.388 & $(-0.521 \div-0.238)$ & -0.066 & $(-0.076 \div-0.055)$ & $<0.0001$ \\
\hline SD & -0.415 & $(-0.544 \div-0.268)$ & -0.073 & $(-0.084 \div-0.062)$ & $<0.0001$ \\
\hline
\end{tabular}




\begin{tabular}{|l|l|l|l|l|l|}
\hline GQoL & -0.396 & $(-0.528 \div-0.247)$ & -0.067 & $(-0.077 \div-0.057)$ & $<0.0001$ \\
\hline
\end{tabular}

Table 4: Correlation between quality of life 6 months following PCI (MacNew) and depression (BDI) at week one following PCI in 140 patients after 6 months.

ED-Emotional Dimension; PD - Physical Dimension; SD - Social Dimension;GQoL - General Quality of Life

All Spearman correlation coefficients $(\mathrm{rS})$ in Table 4 are significantly different from zero at $\mathrm{P}<0.0001$. A higher score on the BDI at week one was correlated with a lower score on the MacNew evaluating quality of life after 6 months.

Because differences with regard to variables of the sociodemographic and clinical characteristics of the groups were statistically significant, multiple regression analysis was used to analyse the predictors in which the groups differed. The purpose of the analysis was to determine whether lower quality of life in the depressed patients was or was not in any way correlated with the differences found and interaction between the predictors.

The effect of the following predictors was taken into consideration in evaluating quality of life after 6 months:

- age; sex being female;

- marital status being single (spinster, widow, divorced);

- diabetes;

- Depressive symptoms evaluated at week one after PCI using the BDI questionnaire.

The following types of correlation with quality of life after 6 months were found:

$$
\begin{aligned}
& \operatorname{MacNew}_{(\text {General Score })}=5.24-0.063-\mathrm{BDI} \\
& \mathrm{MacNew}_{(\text {Emotional Dimension })}=5.66-0.064-\mathrm{BDI} ; \\
& \mathrm{Mac} \mathrm{New}_{(\text {Physical Dimension })}=4.78-0.060-\mathrm{BDI} \\
& \mathrm{Mac} \mathrm{New}_{(\text {Social Dimension })}=5.45-0.067-\mathrm{BDI}
\end{aligned}
$$

Lower quality of life in all Mac New domains was correlated with depressive symptoms (BDI) evaluated at week one. The effect of age, sex, marital status (single), and diabetes were not found to be statistically significant.

\section{Discussion}

We used the Mac New specific questionnaire as an evaluation tool to allow us to measure heart-related quality of life in patients with ACS. This evaluation tool juxtaposes quality of life with typical cardiological symptoms, such as chest pain, fatigue, reduced physical and social activity due to heart problems, dizziness, loss of balance, dyspnoea, anxiety, and leg pain.

According to many sources, the fear associated with the experience of heart attack may continue to have a destructive effect on various aspects of human health even several years after cardiac infarction. $[14,15]$ The available data suggest that depression and anxiety are the most important factors raising mortality in a low-risk group of patients from 7 years following myocardial infarction [16].

Early diagnosis of depression among ACS patients should prompt therapeutic intervention and thereby help improve quality of life in ACS patients.
Our patients were examined with Beck Depression Inventory (BDI), i.e. with screening tool which is used to assess the severity of depressive symptoms and mood disorders rather than to determine the prevalence of depression. Along with the recommendation of the BDI's authors and protocols of many previous studies, we used the 10 point score as the cut-off value distinguishing between patients who presented with depressive symptoms ( $>10$ points) and those who did not ( $\leq 10$ points). Therefore, the value of $63 \%$ does not correspond to the prevalence of depression.

Our study found that symptoms of depression was observed in almost $60 \%$ of patients hospitalized for ACS during the early hospitalization period and in $27 \% 6$ months after cardiac infarction. These results are in line with studies performed by Whang [13] which found that depression was present among $56 \%$ of patients hospitalized for unstable angina $(29 \%$ of patients with moderate depressive symptoms, $27 \%$ of those with mild symptoms), and with studies by Luttik et al. which assessed depression two months after hospitalization at a department of cardiology, and found that it was present in $26 \%$ of the patients evaluated [17]. Similar results were obtained by Fauerbach et al. - depression was observed in $22.5 \%$ of patients at four months following ACS. [2]

As stated above, we analyzed the severity of depressive symptoms and mood disorders rather than the prevalence of depression. Furthermore, one can hardly conclude on any direct anti-depressive effect of angioplasty; lower severity of depressive symptoms documented on follow-up probably resulted from the holistic care offered after the procedure, e.g. education and counselling regarding physical activity, diet and cessation of smoking, as well as from regular screening at cardiology outpatient clinic.

In our study, both at baseline and follow-up, quality of life scores were significantly lower for patients with symptoms of depression than patients without. Lower scores were obtained in all domains of the Mac New QoL specific questionnaire (General Quality of Life, ED, PD, $\mathrm{SD})$.

Similar findings were presented by Fauerbach et al. [2] i.e. General Quality of Life scores were lower in patients with depression. The authors described the relationship between depression in ACS patients and lower health related quality of life scores (HRQoL). Both at baseline, i.e. during hospitalization, and after four months patients with depression scored lower on the physical) and mental domains compared with patients without depression [2].

Rumsfeld et al. found that patients with depression have far more frequent and severe symptoms of angina, more serious limitations on physical activity, and significantly lower QoL outcomes compared with patients without depression, evaluated 7 months following acute coronary syndrome [18].

Similarly, de Jonge et al. was found a significant correlation between depression after myocardial infarction and lower quality of life, lower health-related satisfaction, a higher rate of stenocardia, and a higher degree of disability. There was also a strong correlation between preinfarction depression rate and lower quality of life scores three months 
after myocardial infarction. The authors believe that depression is not only related to poorer health, but also has a negative way influence on it. [1]

In many studies were presented significant negative correlation between depression and mental health but not with physical health $[15,19]$

Norris et al. examined simultaneously the influence of sex and depression in ACS patients and found that quality of life scores were significantly lower in the physical and mental domains, while depression level, according to the Beck scale, was significantly higher among women. Lower scores for quality of life in the mental domain in women was correlated significantly with severe depression in these women [20].

In other studies in which depression and fatigue were predictors of low health-related quality of life in both women and men one year after myocardial infarction [21].

However in our own study, the socio-demographic analysis showed that the depressive symptoms group are patients who more often than not are older, single women and with diabetes. While the regression analysis of significant variables showed in our study that age, sex, marital status (single), and diabetes were not correlated statistically significantly with lower quality of life in all MacNew questionnaire domains. On the other hand, depressive symptoms at week one had a statistically significant effect on quality of life outcomes after ACS On the other hand, both at baseline and follow-up depressive symptoms was an independent, significant predictor of lowering the quality of life of the patients. Many available studies rank age and sex amongst the most important determinants of low quality of life outcomes in ischemic heart disease. Uchmanowicz and tobozGrudzien proved that in early and late observations of diabetic patients after acute myocardial infarction an age of above 65 had a statistically significant effect on quality of life outcomes in both the physical and mental domains [22].

Our own studies agree with those carried out by Dias et al. [23] where female sex and depression in ACS patients were predictors of lower quality of life scores in the mental domain. Our own study showed that depressive symptoms can be observed in ACS patients and that it significantly reduces quality of life in these patients. It seems reasonable, therefore, that departments of cardiology employ specialists who are trained in early diagnosis of depression and support. We have identified factors which contribute to depression and believe that both screening and therapeutic programmes should primarily be addressed to older, female patients, especially those who are less educated, unemployed and single. A similar approach is advocated by Luttik et al., who believe that the availability of welltrained professionals should be guaranteed in advance in order to ensure that patients receive accurate treatment after being diagnosed [17].

\section{Study Limitation:}

Limitation of this study is using only a BDI questionnaire, which is not a diagnostic tool to identify depression but only to identifying and monitoring symptoms of depression. NHLBI Working Group in 2004 recommended the BDI as a screening tool for testing and monitoring of depressive symptoms in patients with cardiovascular diseases [24]. A limitation of the questionnaire is that it may overestimate the occurrence of depressive symptoms22. It is necessary to continue the started study in order to check how depression affects further functioning of patients with ACS treated with PCI. Another limitation of the study is the lack of analysis of the impact of the type of myocardial infarction (STEMI compared to NSTEMI) on depressive symptoms and HRQoL. Unfortunately, we not analyze the severity of vascular lesions angiographically documented as a potential determinant of HRQoL which is another limitation of our study.

\section{Conclusions}

Depressive symptoms in ACS patients have a strong negative effect on quality of life both in early and late observations after ACS. Early depressive symptoms, on the other hand, are a statistically significant and independent predictor of a lower quality of life outcome. As such, diagnosis and treatment of depression in patients hospitalized with ACS should become a therapeutic standard.

\section{References}

1. de Jonge P, Spijkerman TA, van den Brink RH, Ormel J (2006) Depression after myocardial infarction is a risk factor for declining health related quality of life and increased disability and cardiac complaints at 12 months. Heart 92: 32-39.

2. Fauerbach JA, Bush DE, Thombs BD, McCann UD, Fogel J, Ziegelstein RC. Depression following acute myocardial infarction: a prospective relationship with ongoing health and function. Psychosomatics. 46 (4): 355-61, 2005

3. Mallik S, Krumholz HM, Lin ZQ, Kasl SV, Mattera JA, et al. (2005) Patients with depressive symptoms have lower health status benefits after coronary artery bypass surgery. Circulation 111: 271-277.

4. van Melle JP, de Jonge P, Spijkerman TA, Tijssen JG, Ormel J, et al (2004) Prognostic association of depression following myocardial infarction with mortality and cardiovascular events: a meta-analysis. Psychosom Med 66: 814-822.

5. Dickstein K, Cohen-Solal A, Filippatos G, et al. European Society of Cardiology, Heart Failure Association of the ESC (HFA), European Society of Intensive Care Medicine (ESICM). ESC Committee for Practice Guidelines (CPG): ESC guidelines for the diagnosis and treatment of acute and chronic heart failure 2008: the Task Force for the diagnosis and treatment of acute and chronic heart failure 2008 of the European Society of Cardiology. Developed in collaboration with the Heart Failure Association of the ESC (HFA) and endorsed by the European Society of Intensive Care Medicine (ESICM). Eur J Heart Fail. 10 (10):933-89, 2008

6. Lane D, Ring C, Lip GY, Carroll D. Depression, indirect clinical markers of cardiac disease severity, and mortality following myocardial infarction. Heart. 91 (4):531-2, 2005

7. de Jonge P, Ormel J, Slaets JP, Kempen GI, Ranchor AV, et al. (2004) Depressive symptoms in elderly patients predict poor adjustment after somatic events. Am J Geriatr Psychiatry 12: 57-64.

8. Spertus JA, McDonell M, Woodman CL, Fihn SD. Association between depression and worse disease-specific functional status in outpatients with coronary artery disease. Am Heart J. 140 (1):105-10, 2000

9. Benyamini Y, Roziner I, Goldbourt U, Drory Y, Gerber Y. Israel Study Group on First Acute Myocardial Infarction. Depression and anxiety following myocardial infarction and their inverse associations with future healthbehaviors and quality of life. Ann Behav Med. ;46(3):310-21, 2013

10. Dias CC, Mateus PS, Mateus C, Bettencourt N, Santos L, et al. (2005) Acute coronary syndrome and depression. Rev Port Cardiol 24: 507-516.

11. Bush DE, Ziegelstein RC, Tayback M, Richter D, Stevens S, et al. (2001) Even minimal symptoms of depression increase mortality risk after acute myocardial infarction. Am J Cardiol 88: 337-341.

12. van Melle JP1, de Jonge P, Ormel J, Crijns HJ, van Veldhuisen DJ, et al. (2005) Relationship between left ventricular dysfunction and depression following myocardial infarction: data from the MIND-IT. Eur Heart J 26: 2650-2656. 
Citation: Beata JP, Izabella U, Krzyszt0of U, Krystyna LG (2014) Impact of Depression on Quality of Life Results in Patients Following Acute Coronary Syndrome Treated with Percutaneous Coronary Intervention (PCI). J Nurs Care 3: 222. doi:10.4172/2167-1168.1000222

Page 7 of 7

13. Whang W, Peacock J, Soto AV, et al. Relationship between premature ventricular complexes and depressive symptoms in non-ST-elevation acute coronary syndrome. Eur Heart J Acute Cardiovasc Care;2(1):61-7, 2013 doi: 10.1177/2048872613476101.

14. Ellis JJ, Eagle KA, Kline-Rogers EM, Erickson SR (2005) Depressive symptoms and treatment after acute coronary syndrome. Int J Cardiol 99: 443-447.

15. Myers V, Gerber Y, Benyamini Y, Goldbourt U, Drory Y. Postmyocardial infarction depression: increased hospital admissions and reduced adoption of secondary prevention measures--a longitudinal study. J Psychosom Res;72(1):5-10, 2012

16. Pfiffner D, Hoffmann A (2004) Psychosocial predictors of death for lowrisk patients after a first myocardial infarction: a 7-year follow-up study. J CardiopulmRehabil 24: 87-93.

17. Luttik ML, Jaarsma T, Sanderman R, Fleer J (2011) The advisory brought to practice: routine screening on depression (and anxiety) in coronary heart disease; consequences and implications. Eur J CardiovascNurs 10: 228-233.

18. Rumsfeld JS, Magid DJ, Plomondon ME, Sales AE, Grunwald GK, et al. (2003) History of depression, angina, and quality of life after acute coronary syndromes. Am Heart J 145: 493-499.

19. White ML, Groh CJ (2007) Depression and quality of life in women after a myocardial infarction. J CardiovascNurs 22: 138-144.

20. Norris CM, Hegadoren K, Pilote L (2007) Depression symptoms have a greater impact on the 1-year health-related quality of life outcomes of women post-myocardial infarction compared to men. Eur J CardiovascNurs 6: 92-98.

21. Brink E, Grankvist G, Karlson BW, Hallberg LR (2005) Health-related quality of life in women and men one year after acute myocardial infarction. Qual Life Res 14: 749-757.

22. Uchmanowicz I, Loboz-Grudzien K, Sokalski L. Predictors influencing late Quality of Life of patients with an acute coronary syndrome treated by coronary angioplasty. Eur.J.Cardiovasc.Nurs. 8 (1); s.S11-S12, 2009

23. Dias CC, Mateus P, Santos L, Mateus C, Sampaio F, et al. (2005) Acute coronary syndrome and predictors of quality of life. Rev Port Cardiol 24: 819-831.

24. Lichtman JH, Bigger JT Jr, Blumenthal JA, et al. American Heart Association Prevention Committee of the Council on Cardiovascular Nursing; American Heart Association Council on Clinical Cardiology; American Heart Association Council on Epidemiology and Prevention; American Heart Association Interdisciplinary Council on Quality of Care and Outcomes Research; American Psychiatric Association. Depression and coronary heart disease: recommendations for screening, referral, and treatment: a science advisory from the American Heart Association Prevention Committee of the Council on Cardiovascular Nursing, Council on Clinical Cardiology, Council on Epidemiology and Prevention, and Interdisciplinary Council on Quality of Care and Outcomes Research: endorsed by the American Psychiatric Association. Circulation. 21;118: 1768-75. 